have established a trusting relationship with her psychiatric carers over a 34 year period and the authors must now bear that responsibility. In May 1989, Lord Brandon summarised the Law Lords' decision: "in many cases ... it will not only be lawful for doctors, on the grounds of necessity, to operate on or give other medical treatment to adult patients disabled from giving their consent: it will also be their common law duty to do so." This has been incorporated into the Code of Practice which gives a list of indications for when treatment can be given without consent. The fourth indication (15.8.d.) "otherwise incapable and in need of medical care in circumstances in which he has not declared his unwillingness to be treated prior to the onset of the incapacitating condition," is a very clear indication of how the authors should proceed.

In conclusion, I would manage the case as follows. Firstly, I would review the psychiatric diagnosis and appraise myself of the long-term medical risks if the bladder calculus is left to its own devices. I would then consult with S.T.'s family, her current carers and my peers, followed by an inter-disciplinary case conference with my surgical colleagues and a discussion with the local ethics committee. Hopefully, this would convince all those concerned and particularly the surgeon that the decision to operate was both legally and ethically correct.

RAYMOND F. TRAVERS

The Scott Clinic

Rainhill Hospital,

Prescot, Merseyside

L35 $4 P Q$

\section{A psychiatrist with beds ...}

DeAR SIRS

Professor Cox's excellent article (Psychiatric Bulletins $1991,15,684-686)$ prompts me to report on a recent survey in our district of general practitioners in which they were asked to name three key elements which they felt a psychiatric service should provide.

These were, in order of importance:

(a) rapid response to acute psychiatric crises, with the ability to admit patients whenever necessary to the psychiatric wards of our DGH unit

(b) skilled consultant assessment of psychiatric out-patient referrals

(c) provision of speedy counselling and psychotherapy services when necessary.

It is perhaps ironic that the newest specialist section of the College, and one that is perhaps most uncertain of its identity, represents the service that is most highly valued by general practitioners. My impression is that, so far from being generals, most general psychiatrists feel more like foot soldiers!
Perhaps the first war that needs to be waged is that of semantics. In our district we resolutely resist the dichotomising of 'hospital' and 'community' and insist that the hospital is part of the community. One only has to pass through the hospital foyer on a busy day or to try to find parking space in the hospital car park to see the truth of this.

I suggest the general psychiatry section seriously considers renaming itself 'Section of Acute Psychiatry' or alternatively merging (federally of course) with the Social and Community Psychiatry section.

\section{North Devon District Hospital \\ Barnstaple EX31 4JB} JEREMY HOLMES

\section{DeAr SirS}

The results of Dr Jeremy Holme's survey of his District's general practitioners in which they were asked the name of those elements which they felt a psychiatric service should provide, causes us no surprises. Interestingly, a recent survey done by Dr Tom Burns, Secretary of the Community Psychiatry Section, revealed similar findings. General practitioners require a speedy response to acute psychiatric crises as they are wont to receiving from our general physician and surgical colleagues. GPs are aware of the pitfalls of psychiatric diagnosis and further, regret the over-emphasis on medication and welcome the access that psychiatrists have to counselling and psychotherapy services.

Dr Holme's second point is more problematical. Like him, we resist the dichotomy of hospital and community. We also accept that there is at least a debate that the General Psychiatry Section might merge with the Social and Community Psychiatry Section. Federalism, as our political masters have repeatedly pointed out, has different meanings for different people. If such a merger was to be considered, then, perhaps a confederation would be more relevant, each Section retaining considerable autonomy.

We recognise that the Section of General Psychiatry is not a good term and claim no responsibility for this title. Nevertheless, the name of our Section has not deterred over 3,000 Members and Fellows of the College from signing up. Unfortunately, other titles may be worse and Dr Holmes's suggestion that we should be re-christened the "Section of Acute Psychiatry" would probably irritate our Community and Social Psychiatry colleagues - and child psychiatrists may not be happy either. Perhaps a Section of General Adult Psychiatry would better represent our clinical interests with regard to the age of our patients and the specialist skills we possess. We would welcome the advice of your readers.

JoHN L. Cox (Chairman)

J. HuBert LACEY (Secretary) General Psychiatry Section 